Review

\title{
An Exoplanet has Smothering Stratosphere without Water
}

\author{
${ }^{1}$ Relly Victoria Petrescu, ${ }^{2}$ Raffaella Aversa, ${ }^{2}$ Antonio Apicella and ${ }^{1}$ Florian Ion Tiberiu Petrescu \\ ${ }^{1}$ ARoTMM-IFToMM, Bucharest Polytechnic University, Bucharest, (CE), Romania \\ ${ }^{2}$ Department of Architecture and Industrial Design, Advanced Material Lab, \\ Second University of Naples, 81031 Aversa (CE), Italy
}

Article history

Received: 13-01-2018

Revised: $16-01-2018$

Accepted: 22-01-2018

Corresponding Author: Florian Ion Tiberiu Petrescu ARoTMM-IFToMM, Bucharest Polytechnic University, Bucharest, (CE), Romania

E-mail: scipub02@gmail.com
Abstract: In some earlier works, the authors of the present study have shown that a modern ship should resemble a UFO, an accelerated particle jet propulsion with a particle accelerator on board the ship, accelerating to the very best big. The problem as an idea is clear and simple, but the current technologies we have in the field of fixed particle circular accelerators with which we are working for about 50-60 years on earth are very backward. Here we are somewhere at the beginning of the circular particle accelerator era, in the sense that although we have built such bigger and stronger devices, the technologies used resemble those of the $1960 \mathrm{~s}$, so to get huge energies is not enough to prepare more particle passes, but to increase the diameter of the accelerator permanently. This prevents the real construction of a modern circular accelerator of mobile particles that can be mounted on a modern land-based ship. The electronics of the last 20 years have brought some improvements, particularly visible to CERN, but they are still insignificant, so for the development of very powerful, accelerators that can generate particle flows capable of moving an ultra modern ship is still there a long way. I have also stated in other papers in this field that due to the current situation, in order not to waste too much time waiting for our physicists and specialists in electronics to successfully solve these inconveniences that have been dragging in the $1960 \mathrm{~s}$, it is necessary to quickly orient ourselves to ships propelled with modern lasers, very strong and especially with very high frequencies, repeating the impulses once every 10-15 s. Modern lasers can quickly pull us out of this impasse and help us build modern, dreamlike ships that reach speeds close to that of light in the best conditions. Until fusion nuclear reactors are well established, we can also use fission power combined with photovoltaic stellar energy. NASA has a note of 10 with congratulations because it has managed to create powerful photovoltaic nets capable of capturing very large energies, concentrated from the dim light of the cosmos from the various stars. At the moment, the most important thing is to build ultra-fast, modern, maneuverable ships to begin exploring our solar system quickly, then our galaxy and finally the universe. We need a star fleet to navigate the entire space of our galaxy quickly, to travel to different stars, planets, satellites, to begin exploring in real time the real universe and then the farthest. Let's start moving to the exoplanets already discovered in real time. For starters, a speed close to that of light will be enough until we are able to find a way to move faster. Energy is another important objective for conquering space. We need energy not only to move ourselves kidnapped through interstellar space, but also to build bases on different planets or satellites, or to begin grounding important planets close to us. A first planet that will need to be tertiary immediately is our neighbor Mars.

Keywords: NASA, Exoplanet, Atmosphere, Stratosphere, Water, Modern Ships

(C) 2018 Relly Victoria Petrescu, Raffaella Aversa, Antonio Apicella and Florian Ion Tiberiu Petrescu. This open access article is distributed under a Creative Commons Attribution (CC-BY) 3.0 license. 


\section{Introduction}

On Earth, ozone absorbs UV in the stratosphere, protecting our world from much of the harmful radiation of the Sun. For a stratospheric exoplaner, the absorbent is usually considered to be a molecule like titanium oxide, a near-titanium dioxide relative to Earth as a paint pigment and a sunscreen.

Researchers analyzed the data collected for the WASP-18b (Fig. 1), located at 325 light-years from Earth, as part of a survey to find exoplanets with the stratosphere. The heavy planet, which has ten times the mass of the planet Jupiter, has been observed repeatedly, allowing astronomers to accumulate a relatively large volume of data. This study analyzed five eclipses from Hubble's archived data and two from Spitzer.

From light emitted by the planet's atmosphere to infrared wavelengths, beyond the visible region, it is possible to identify spectral watermarks and other important molecules. The analysis has revealed the typical WASP-18b footprint, which does not resemble any exoplanet examined so far. To determine which of the molecules were most likely to match it, the team performed computerized modeling.

"The only consistent explanation of the data is a carbon monoxide overlap and very few water vapors in the WASP-18b atmosphere, in addition to the presence of a stratosphere," said Nikku Madhusudhan, co-author of the University of Cambridge, UK. This rare combination of factors opens a new window in our understanding of physical and chemical processes in exoplanetary atmospheres.

The results show that WASP-18b has hot carbon monoxide in the stratosphere and cooler carbon monoxide in the atmosphere below, called the troposphere. The team determined this by detecting two types of carbon monoxide signatures, an absorption signature at a wavelength of about 1.6 microns and an emission signature at about 4.5 microns. This is the first time scientists have detected both types of fingerprints for a single type of molecule in an exoplanet atmosphere.

In theory, another possibility for observations is carbon dioxide, which has a similar fingerprint. Researchers have decided this because if there is enough oxygen available to form carbon dioxide, the atmosphere should also have water vapor.

To produce spectral impressions seen by the team, the top atmosphere of WASP-18b should be loaded with carbon monoxide. Compared to other planets similar to Jupiter, the atmosphere of this planet could contain 300 times more "metals" or heavier elements than hydrogen and helium. This extremely high metality would indicate that WASP-18b could have accumulated larger amounts of solid frost during its formation than Jupiter, suggesting it might not have been formed in the way other hot Jupiters were made.

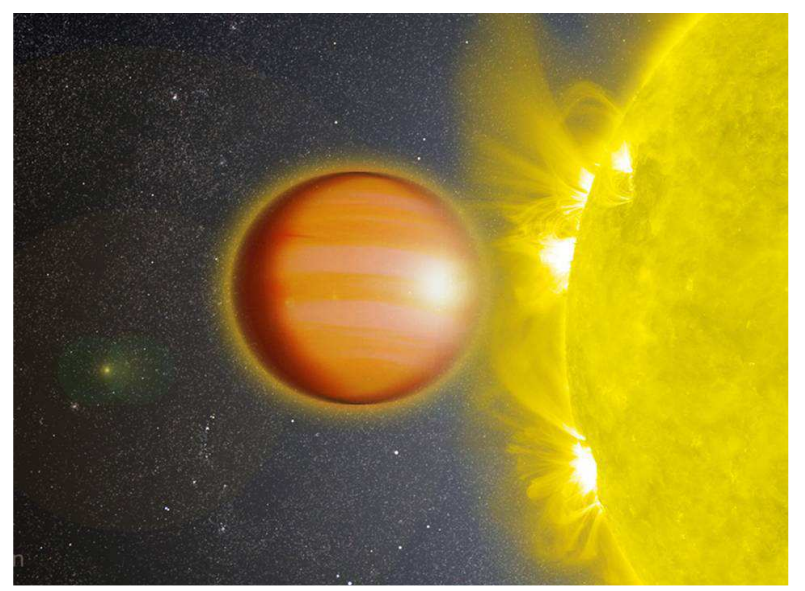

Fig. 1: WASP-18b, a "hot Jupiter" located 325 light-years from Earth, has a stratosphere that's loaded with carbon monoxide but has no signs of water

"The expected launch of the James Webb Space Telescope and other future space observers will provide us with the opportunity to continue research with even more powerful tools and continue exploring the huge range of exoplanets," said Avi Mandell, a scientist in the Goddard exodus field and the second author of the work (Zubritsky, 2017; Aversa et al., 2017a; 2017b; 2017c; 2017d; 2017e; 2016a; 2016b; 2016c; 2016d; 2016e; 2016f; 2016g; 2016h; 2016i; 2016j; 2016k; 2016l; 2016m; 2016n; 2016o; Berto et al., 2016a; 2016b; 2016c; 2016d; Mirsayar et al., 2017; Petrescu and Petrescu, 2016a; 2016b; 2016c; 2013a; 2013b; 2013c; 2013d; 2012a; 2012b; 2012c; 2012d; 2011a; 2011b; Petrescu, 2016; 2012a; 2012b; 2009; Petrescu and Calautit, 2016a; 2016b; Petrescu et al., 2016a; 2016b; 2016c; Petrescu et al., 2017a; 2017b; 2017c; 2017d; 2017e; 2017f; 2017g; 2017h; 2017i; 2017j; 2017k; 2017l).

\section{Materials and Methods}

WASP-18 is a magnitude 9 star located in the southern hemisphere Phoenix constellation. It has a mass of 1.25 masses of sun.

In 2009, the SuperWASP project announced that an extra-large planet type Jupiter, WASP-18b, was in orbit very close to this star.

Observations from the Chandra observer have failed to find WASP-18 X-rays and it is believed that this is caused by the destruction of the magnetic field of the star by reducing the convection in the star atmosphere. Tidal forces on the planet can also explain the higher quantities of lithium measured in previous WASP-18 optical studies.

WASP-18b is an extrasolar planet that is notable for an orbital period of less than a day. It has a mass equal to 10 Jupiter masses, just below the boundary line between planets and brown dwarfs, about 13 Jupiter masses. Due to the tidal deceleration, it is expected to approach and 
eventually merge with the host star, WASP-18, in less than a million years. The planet is about 3.1 million kilometers (1.9 million miles) from its star, which is about 325 light years away from Earth. It was discovered by a team led by Coel Hellier, professor of astrophysics at Keele University in England.

Keele scientists and the University of Maryland are trying to understand if the discovery of this planet so short of its expected disappearance (with less than $0.1 \%$ of the remaining lifetime) was forcible or if tide dissipation By WASP-18 is actually much less effective than astrophysics usually suppose. Observations made over the next decade should determine the rate at which the WASP-18b orbit decomposes.

The closest example of a similar situation in the solar system is Phobos moon of Mars. Phobos orbits Mars at a distance of just $9,000 \mathrm{~km}, 40$ times closer to the Earth than Earth and is expected to be destroyed in about eleven million years.

\section{Results}

WASP or Wide Angle Search for Planets is an international consortium of several academic organizations with the task of conducting repetitive ultrawide angle searches for the obvious purpose of finding exoplanets using the procedure called transit photometry. It is equipped with a range of robotic telescopes to watch the entire sky simultaneously, instantly monitoring and at the same time many thousands of stars with a visible visual magnitude from 7 to 13 .

WASP is an Isaac Newton, IAC and six other UK universities space detection program. There are two large observatories that operate continuously, robotic, to cover at the same time both the Northern and the Southern hemisphere. The SuperWASP North is positioned at the Roque de Los Muchachos Observatory on the island of La Palma in Canary Island, Spain, while South WASP is located on the site of the South African Astronomical Observatory near Sutherland, South Africa. Each of the two observers uses eight wide angle cameras that simultaneously monitor the sky for planetary transit events and allow the monitoring of millions of stars simultaneously, allowing for the detection of very rare transit events.

The instruments used use Doppler spectroscopy for tracking characterization and to determine the mass of the exoplanet, including the HARPS spectrograph of the ESO telescope of $3.6 \mathrm{~m}$ and the Euler Swiss Telescope, both located at La Silla Observatory in Chile.

Due to its special features, the new WASP project was also adopted by the Next Generation Transit Study. Starting in 2016, the Extrasolar Planets Encyclopaedia database contains a total of 2,107 extrasolar planets, 118 of which are discovered using the WASP system.
Each of the two robotized and automated WASP (Northern and Southern) giant observer giant observatories consists of a range of eight Canon $200 \mathrm{~mm}$ f1. 8 lenses, supported by $2048 \times 2048$ high-quality CCDs, the model being used iKon-L manufactured by Andor Technology. Telescopes are mounted on a telescopic pole, built by Optical Mechanics Inc. Canon's high field of vision provides each observer with a massive sky coverage of 490 square degrees per point.

If in the past we were thinking of spending a lot of money on devices designed to capture a possible alien signal, here we are several steps ahead and we no longer wait for someone or something to give us something or to be helped or to have some luck to give us a sign somewhere. Today we are well anchored in reality and we want to look for ourselves the possible living planets in the whole universe. There were skeptics who taught us that there are no other planets in the universe and our unique planet is the only habitable place. Not just the periods in which mankind stood in the dark, or it was pastored with the fear of not seeking, were heavy for all, but even the modern age in which much was lost with expectations, more than with concrete actions, as we are doing them more and more today. We have just woken up from a sleep like the beautiful ones in the sleeping forest and realize that we can and that we have to move, act, conquer the universe we are in, because we already have many of the necessary technologies already put in place to the point and we have all the forces in unison, ready to act on a single favorable signal. The purpose of man to conquer the cosmic space, the surrounding universe and then it begins to be done, little by little but surely. We finally awakened from our dreams and we decided to take our fate into our hands. I realized that man is not meant to just eat, drink and possibly spend. Today more than ever we realize that we must define ourselves as humanity, fulfill ourselves and stretch ourselves to new, mature, important goals. We need technology, government and planetary funds, new modern ships with special capabilities, strong stationary and mobile telescopes, increasingly fast communications, robots and weapons capable of helping us with this important step, exploring and conquering the universe. The important thing is that we already started.

WASP observers constantly monitor the sky by performing one set of images approximately once per minute (probably the pace will be even faster in the future), managing to collect up to about 100 gigabytes of data in one night. Due to the use of the transit method, all data collected by WASP systems can be used to measure the luminosity of each star for each image and so can be searched for small diminutions of brightness caused by large planets that pass through the front stars.

One of WASP's main goals on the lamga discovery of exoplanets was to revolutionize the understanding of 
planet formation, thus preparing the way for future new space missions that will search for worlds similar to those of the Earth.

On September 26, 2006, the team reported the discovery of two extrasolar planets: WASP-1b (orbiting 6 million kilometers from stars once every 2.5 days) and WASP-2b (orbiting 4.5 million $\mathrm{km}$ of star once 2 days).

On October 31, 2007, the team reported the discovery of three extrasolar planets: WASP-3b, WASP-4b and WASP-5b. All three planets are similar to the Jovian mass and are so close to the stars that their orbital periods are all less than two days old. These are among the shortest orbital periods discovered. Surface temperatures of the planets should be higher than 2000 degrees Celsius, due to short distances to the stars. The WASP-4b and WASP-5b are the first planets discovered by the WASP cameras in South Africa, while WASP-3b is the third planet discovered by the WASP project rooms in La Palma.

In August 2009, the WASP-17b discovery, considered to be the first planet discovered in orbit in the opposite direction of its star, WASP-17, was announced.

WASP 1 is a metal-rich star of magnitude 12 , located in the Andromeda constellation at about 1,240 lightyears away from Earth.

WASP-8 is a 9.9 magnitude yellow star at 160 light years from Terra. It is believed to be a G-star with a temperature of $5600 \mathrm{~K}$, a mass of 0.93 masses of sun, a radius of 0.93 sunshine and a brightness of 0.79 of sunlight.

The star is orbited by two known extrasolar planets, called WASP-8b and WASP-8c. They were cataloged as part of the SuperWASP mission and were discovered by the astronomical transit method. WASP-8c has the longest orbital period of any WASP-discovered exoplanet with a 4323-day period, over 400 times greater than that of WASP-117b with a 10.02-day period.

WASP-8b radius and mass measurements give it an estimated density of $2.53 \mathrm{~g} / \mathrm{cm}^{3}$, approximately double the density of Jupiter.

About 30-40 years ago we were believed to be alone in the Universe and here we have just begun research and over 2100 planets have been discovered to be inhabited, at different distances from Earth, somewhere in the Universe. Research has accelerated considerably and will continue to accelerate. We now have performance systems for this purpose. Super terrestrial telescopes, other mobile telescopes mounted on ships long gone into outer space. Probably in the future we will mount powerful telescopes on satellites or even on other planets.

The need to build ultra-fast ships quickly pushes us from the back, so research is now much advanced in several countries of the world, starting with the US, UK, Canada, France, Germany, China, Russia, Italy.

\section{Discussion}

In some earlier works, the authors of the present study have shown that a modern ship should resemble a UFO, an accelerated particle jet propulsion with a particle accelerator on board the ship, accelerating to the very best big. The problem as an idea is clear and simple, but the current technologies we have in the field of fixed particle circular accelerators with which we are working for about 50-60 years on earth are very backward. Here we are somewhere at the beginning of the circular particle accelerator era, in the sense that although we have built such bigger and stronger devices, the technologies used resemble those of the 1960 s, so to get huge energies is not enough to prepare more particle passes, but to increase the diameter of the accelerator permanently. This prevents the real construction of a modern circular accelerator of mobile particles that can be mounted on a modern land-based ship. The electronics of the last 20 years have brought some improvements, particularly visible to CERN, but they are still insignificant, so for the development of very powerful, accelerators that can generate particle flows capable of moving an ultra modern ship is still there a long way. I have also stated in other papers in this field that due to the current situation, in order not to waste too much time waiting for our physicists and specialists in electronics to successfully solve these inconveniences that have been dragging in the 1960s, it is necessary to quickly orient ourselves to ships propelled with modern lasers, very strong and especially with very high frequencies, repeating the impulses once every 10-15 s.

Modern lasers can quickly pull us out of this impasse and help us build modern, dreamlike ships that reach speeds close to that of light in the best conditions. Until fusion nuclear reactors are well established, we can also use fission power combined with photovoltaic stellar energy. NASA has a note of 10 with congratulations because it has managed to create powerful photovoltaic nets capable of capturing very large energies, concentrated from the dim light of the cosmos from the various stars.

At the moment, the most important thing is to build ultra-fast, modern, maneuverable ships to begin exploring our solar system quickly, then our galaxy and finally the universe.

We need a star fleet to navigate the entire space of our galaxy quickly, to travel to different stars, planets, satellites, to begin exploring in real time the real universe and then the farthest. Let's start moving to the exoplanets already discovered in real time. For starters, a speed close to that of light will be enough until we are able to find a way to move faster.

Energy is another important objective for conquering space. We need energy not only to move ourselves kidnapped through interstellar space, but also to build 
bases on different planets or satellites, or to begin grounding important planets close to us. A first planet that will need to be tertiary immediately is our neighbor Mars.

\section{Conclusion}

At the moment, the most important thing is to build ultra-fast, modern, maneuverable ships to begin exploring our solar system quickly, then our galaxy and finally the universe.

We need a star fleet to navigate the entire space of our galaxy quickly, to travel to different stars, planets, satellites, to begin exploring in real time the real universe and then the farthest. Let's start moving to the exoplanets already discovered in real time. For starters, a speed close to that of light will be enough until we are able to find a way to move faster.

Energy is another important objective for conquering space. We need energy not only to move ourselves kidnapped through interstellar space, but also to build bases on different planets or satellites, or to begin grounding important planets close to us. A first planet that will need to be tertiary immediately is our neighbor Mars.

\section{Acknowledgement}

We acknowledge and thank $\mathrm{Mr}$ Taher M. AbuLebdeh, Associate Prof at North Carolina A and T State Univesity, United States and Mr Muftah H. El-Naas PhD MCIC FICCE QAFCO Chair Professor in Chemical Process Engineering Gas Processing Center College of Engineering Qatar University and Ms Shweta Agarwala, Senior Research Scientist at Singapore Center for 3D Printing Nanyang Technological University Singapore for their suggestions and comments.

\section{Funding Information}

Research contract: Contract number 36-5-4D/1986 from 24IV1985, beneficiary CNST RO (Romanian National Center for Science and Technology) Improving dynamic mechanisms internal combustion engines. All these matters are copyrighted. Copyrights: 548cgiywDssin, from: 22-04-2010, 08:48:48.

\section{Author's Contributions}

All the authors contributed equally to prepare, develop and carry out this manuscript.

\section{Ethics}

This article is original and contains unpublished material. The corresponding author confirms that all of the other authors have read and approved the manuscript and no ethical issues involved.

\section{References}

Aversa, R., F.I.T. Petrescu, R.V. Petrescu and A. Apicella, 2016a. Biomimetic FEA bone modeling for customized hybrid biological prostheses development. Am. J. Applied Sci., 13: 1060-1067. DOI: 10.3844/ajassp.2016.1060.1067

Aversa, R., D. Parcesepe, R.V. Petrescu, G. Chen and F.I.T. Petrescu et al., 2016b. Glassy amorphous metal injection molded induced morphological defects. Am. J. Applied Sci., 13: 1476-1482. DOI: 10.3844 /ajassp.2016.1476.1482

Aversa, R., R.V. Petrescu, F.I.T. Petrescu and A. Apicella, 2016c. Smart-factory: Optimization and process control of composite centrifuged pipes. Am. J. Applied Sci., 13: 1330-1341.

DOI: 10.3844/ajassp.2016.1330.1341

Aversa, R., F. Tamburrino, R.V. Petrescu, F.I.T. Petrescu and M. Artur et al., 2016d. Biomechanically inspired shape memory effect machines driven by muscle like acting NiTi alloys. Am. J. Applied Sci., 13: 1264-1271.

DOI: 10.3844/ajassp.2016.1264.1271

Aversa, R., E.M. Buzea, R.V. Petrescu, A. Apicella and M. Neacsa et al., 2016e. Present a mechatronic system having able to determine the concentration of carotenoids. Am. J. Eng. Applied Sci., 9: 1106-1111. DOI: 10.3844/ajeassp.2016.1106.1111

Aversa, R., R.V. Petrescu, R. Sorrentino, F.I.T. Petrescu and A. Apicella, 2016f. Hybrid ceramo-polymeric nanocomposite for biomimetic scaffolds design and preparation. Am. J. Eng. Applied Sci., 9: 1096-1105. DOI: 10.3844/ajeassp.2016.1096.1105

Aversa, R., V. Perrotta, R.V. Petrescu, C. Misiano and F.I.T. Petrescu et al., 2016g. From structural colors to super-hydrophobicity and achromatic transparent protective coatings: Ion plating plasma assisted $\mathrm{TiO}_{2}$ and $\mathrm{SiO}_{2}$ Nano-film deposition. Am. J. Eng. Applied Sci., 9: 1037-1045. DOI: 10.3844/ajeassp.2016.1037.1045

Aversa, R., R.V. Petrescu, F.I.T. Petrescu and A. Apicella, 2016h. Biomimetic and evolutionary design driven innovation in sustainable products development. Am. J. Eng. Applied Sci., 9: 1027-1036. DOI: 10.3844/ajeassp.2016.1027.1036

Aversa, R., R.V. Petrescu, A. Apicella and F.I.T. Petrescu, 2016i. Mitochondria are naturally micro robots-a review. Am. J. Eng. Applied Sci., 9: 991-1002. DOI: 10.3844/ajeassp.2016.991.1002

Aversa, R., R.V. Petrescu, A. Apicella and F.I.T. Petrescu, 2016j. We are addicted to vitamins $\mathrm{C}$ and E-A review. Am. J. Eng. Applied Sci., 9: 1003-1018. DOI: 10.3844/ajeassp.2016.1003.1018 
Aversa, R., R.V. Petrescu, A. Apicella and F.I.T. Petrescu, 2016k. Physiologic human fluids and swelling behavior of hydrophilic biocompatible hybrid ceramo-polymeric materials. Am. J. Eng. Applied Sci., 9: 962-972.

DOI: 10.3844/ajeassp.2016.962.972

Aversa, R., R.V. Petrescu, A. Apicella and F.I.T. Petrescu, 20161. One can slow down the aging through antioxidants. Am. J. Eng. Applied Sci., 9: 1112-1126. DOI: 10.3844/ajeassp.2016.1112.1126

Aversa, R., R.V. Petrescu, A. Apicella and F.I.T. Petrescu, 2016m. About homeopathy or «Similia similibus curentur $\gg$. Am. J. Eng. Applied Sci., 9: 1164-1172. DOI: 10.3844/ajeassp.2016.1164.1172

Aversa, R., R.V. Petrescu, A. Apicella and F.I.T. Petrescu, 2016n. The basic elements of life's. Am. J. Eng. Applied Sci., 9: 1189-1197.

DOI: 10.3844/ajeassp.2016.1189.1197

Aversa, R., F.I.T. Petrescu, R.V. Petrescu and A. Apicella, 2016o. Flexible stem trabecular prostheses. Am. J. Eng. Applied Sci., 9: 1213-1221. DOI: 10.3844/ajeassp.2016.1213.1221

Aversa, R., R.V.V. Petrescu, A. Apicella and F.I.T. Petrescu, 2017a. Nano-diamond hybrid materials for structural biomedical application. Am. J. Biochem. Biotechnol., 13: 34-41.

DOI: 10.3844/ajbbsp.2017.34.41

Aversa, R., R.V. Petrescu, B. Akash, R.B. Bucinell and J.M. Corchado et al., 2017b. Kinematics and forces to a new model forging manipulator. Am. J. Applied Sci., 14: 60-80. DOI: 10.3844/ajassp.2017.60.80

Aversa, R., R.V. Petrescu, A. Apicella, I.T.F. Petrescu and J.K. Calautit et al., 2017c. Something about the $\mathrm{V}$ engines design. Am. J. Applied Sci., 14: 34-52. DOI: 10.3844/ajassp.2017.34.52

Aversa, R., D. Parcesepe, R.V.V. Petrescu, F. Berto and G. Chen et al., 2017d. Process ability of bulk metallic glasses. Am. J. Applied Sci., 14: 294-301. DOI: 10.3844/ajassp.2017.294.301

Aversa, R., R.V.V. Petrescu, B. Akash, R.B. Bucinell and J.M. Corchado et al., 2017e. Something about the balancing of thermal motors. Am. J. Eng. Applied Sci., 10: 200-217. DOI: 10.3844/ajeassp.2017.200.217

Berto, F., R.V.V. Petrescu and F.I.T. Petrescu, 2016a. A review of recent results on $3 \mathrm{D}$ effects. Am. J. Eng. Applied Sci., 9: 1247-1260.

Berto, F., R.V.V. Petrescu and F.I.T. Petrescu, 2016 b. Three-dimensional in bonded joints: A short review. Am. J. Eng. Applied Sci., 9: 1261-1268.

Berto, F., A. Gagani, R.V.V. Petrescu and F.I.T. Petrescu, 2016c. Key-hole notches in isostatic graphite: A review of some recent data. Am. J. Eng. Applied Sci., 9: 1292-1300.
Berto, F., A. Gagani, R. Aversa, R.V.V. Petrescu and A. Apicella et al., 2016d. Multiaxial fatigue strength to notched specimens made of 40CrMoV13.9. Am. J. Eng. Applied Sci., 9: 1269-1291.

Mirsayar, M.M., V.A. Joneidi, R.V.V. Petrescu, F.I.T. Petrescu and F. Berto, 2017. Extended MTSN criterion for fracture analysis of soda lime glass. Eng. Fracture Mechanics, 178: 50-59.

DOI: $10.1016 /$ j.engfracmech.2017.04.018

Petrescu, F.I.T. and J.K. Calautit, 2016a. About nano fusion and dynamic fusion. Am. J. Applied Sci., 13: 261-266.

Petrescu, F.I. and J.K. Calautit, 2016b. About the light dimensions. Am. J. Applied Sci., 13: 321-325. DOI: 10.3844 /ajassp.2016.321.325

Petrescu, F.I. and R.V. Petrescu, 2011 a. Memories about Flight. 1st Edn., CreateSpace, pp: 652.

Petrescu, F.I. and R.V. Petrescu, 2011b. Mechanical Systems, Serial and Parallel.1st Edn., lulu.com Publisher, London, UK, ISBN-10: 1446600394, pp: 124.

Petrescu, R.V. and F.I.T. Petrescu, 2012a. Northrop. 1st Edn., Books on Demand, ISBN-10: 3848209322 , pp: 142.

Petrescu, F.I. and R.V. Petrescu, 2012b. New Aircraft II. 1 st Edn., Books on Demand, pp: 138.

Petrescu, F.I. and R.V. Petrescu, 2012c. MecatronicaSisteme Seriale Si Paralele. 1st Edn., Create Space Publisher, USA, ISBN-13: 978-1-4750-6613-5, pp: 128.

Petrescu, F.I. and R.V. Petrescu, 2012d. Kinematics of the planar quadrilateral mechanism. ENGEVISTA, 14: $345-348$.

Petrescu, F.I. and R.V. Petrescu, 2016a. Parallel moving mechanical systems kinematics. ENGEVISTA, 18: 455-491.

Petrescu, F.I. and R.V. Petrescu, 2016b. Direct and inverse kinematics to the anthropomorphic robots. ENGEVISTA, 18: 109-124.

Petrescu, F.I. and R.V. Petrescu, 2016c. Dynamic cinematic to a structure 2R. Revista Geintec-Gestao Inovacao E Tecnologias, 6: 3143-3154.

Petrescu, F.I.T., 2009. New aircraft. Proceedings of the 3rd International Conference on Computational Mechanics, Oct. 29-30, Brasov, Romania.

Petrescu, F.I.T., 2012a. Cold Nuclear Fusion. 1st Edn., Create Space, USA, ISBN-10: 1478234261, pp: 80.

Petrescu, F.I.T., 2012b. Particle annihilation - a source of renewable energy? Infinite Energy Magazine, LuLu Publishers, USA. http://blog.hasslberger.com/2012/02/particle_annihil ation_-_a_sour.html

Petrescu, F.I.T. 2016 Valorificarea Traditiei Ingineresti Romanesti-I. 1st Edn., CreateSpace Independent Publishing Platform, ISBN-10: 1536889946, pp: 152. 
Petrescu, R.V. and F.I. Petrescu, 2013a. Lockheed Martin. 1st Edn., CreateSpace, pp: 114.

Petrescu, R.V. and F.I. Petrescu, 2013b. Northrop. 1st Edn., CreateSpace, pp: 96.

Petrescu, R.V. and F.I. Petrescu, 2013c. The Aviation History or New Aircraft I Color. 1st Edn., CreateSpace, pp: 292.

Petrescu, F.I. and R.V. Petrescu, 2013d. Cinematics of the 3R Dyad. Engevista, 15: 118-124.

Petrescu, R.V.V., R. Aversa, A. Apicella, F. Berto and S. Li et al., 2016a. Ecosphere protection through green energy. Am. J. Applied Sci., 13: 1027-1032.

Petrescu, F.I.T., A. Apicella, R.V.V. Petrescu, S.P. Kozaitis and R.B. Bucinell et al., $2016 \mathrm{~b}$. Environmental protection through nuclear energy. Am. J. Applied Sci., 13: 941-946.

Petrescu, R.V., R. Aversa, A. Apicella and F.I. Petrescu, 2016c. Future medicine services robotics. Am. J. Eng. Applied Sci., 9: 1062-1087.

Petrescu, R.V., R. Aversa, B. Akash, F. Berto and A. Apicella et al., 2017a. Forces of a 3R robot. J. Mechatron. Robot., 1: 1-14.

Petrescu, R.V., R. Aversa, B. Akash, F. Berto and A. Apicella et al., 2017b. Direct geometry and cinematic to the MP-3R systems. J. Mechatron. Robot., 1: 15-23.

Petrescu, R.V., R. Aversa, B. Akash, F. Berto and A. Apicella et al., 2017c. Dynamic elements at MP3R. J. Mechatron. Robot., 1: 24-37.

Petrescu, R.V., R. Aversa, B. Akash, F. Berto and A. Apicella et al., 2017d. Geometry and direct kinematics to MP3R with $4 \times 4$ operators. J. Mechatron. Robot., 1: 38-46.

Petrescu, R.V., R. Aversa, A. Apicella, M.M. Mirsayar and S. Kozaitis et al., 2017e. Current stage in the field of mechanisms with gears and rods. J. Mechatron. Robot., 1: 47-57.

Petrescu, R.V., R. Aversa, A. Apicella, M.M. Mirsayar and S. Kozaitis et al., 2017f. Geometry and inverse kinematic at the MP3R mobile systems. J. Mechatron. Robot., 1: 58-65.
Petrescu, R.V., R. Aversa, A. Apicella, M.M. Mirsayar and S. Kozaitis et al., 2017g. Synthesis of optimal trajectories with functions control at the level of the kinematic drive couplings. J. Mechatron. Robot., 1: 66-74.

Petrescu, R.V., R. Aversa, A. Apicella, M.M. Mirsayar and S. Kozaitis et al., 2017h. The inverse kinematics of the plane system 2-3 in a mechatronic MP2R system by a trigonometric method. J. Mechatron. Robot., 1: 75-87.

Petrescu, R.V., R. Aversa, A. Apicella, M.M. Mirsayar and S. Kozaitis et al., 2017i. Serial, anthropomorphic, spatial, mechatronic systems can be studied more simply in a plan. J. Mechatron. Robot., 1: 88-97.

Petrescu, R.V., R. Aversa, A. Apicella, M.M. Mirsayar and S. Kozaitis et al., 2017j. Analysis and synthesis of mechanisms with bars and gears used in robots and manipulators. J. Mechatron. Robot., 1: 98-108.

Petrescu, R.V., R. Aversa, A. Apicella, M.M. Mirsayar and S. Kozaitis et al., 2017k. Speeds and accelerations in direct kinematics to the MP3R systems. J. Mechatron. Robot., 1: 109-117.

Petrescu, R.V., R. Aversa, A. Apicella, M.M. Mirsayar and S. Kozaitis et al., 20171. Geometry and determining the positions of a plan transporter manipulator. J. Mechatron. Robot., 1: 118-126.

Zubritsky, E., 2017. Exoplanet has smothering stratosphere without water. NASA's Jet Propulsion Laboratory, Pasadena, California Institute of Technology. https://www.jpl.nasa.gov/news/news.php?feature=7 012

\section{Source of Figures}

Fig. 1:

https://www.jpl.nasa.gov/news/news.php?feature $=7012$ 